\title{
The Impact of Flight Profiles Towards EMC on All- Electric Aircraft
}

\author{
Leonardo Malburg \\ University of Twente \\ Enschede, the Netherlands \\ 1.correamalburg@utwente.nl
}

\author{
Niek Moonen \\ University of Twente \\ Enschede, the Netherlands
}

\author{
Frank Leferink \\ University of Twente \\ Enschede, the Netherlands \\ THALES Nederland B.V., \\ Hengelo, the Netherlands
}

\begin{abstract}
All-electric aircraft (AEA) currently experiences an increase in industrial and research initiatives. The implementation of such technology in commercial activities is imminent, however, entirely dependent on technological advancements yet to be achieved. Dealing with a full electric powertrain presents several challenges, amongst which ensuring electromagnetic compatibility (EMC) is one of the most important topics. Therefore, different permanent magnet synchronous motor operational speeds were evaluated in a simulation to determine their impact on generated electromagnetic interference (EMI). Thus, different emission levels originating from the implemented speeds will impact the mitigation design strategy, leading to the development of proper solutions.
\end{abstract}

Keywords-All-electric aircraft, Electromagnetic interference (EMI), Electromagnetic compatibility (EMC), Flight Profile, Electric powertrain

\section{INTRODUCTION}

The all-electric aircraft (AEA) industry currently experiences an increasing number of initiatives, characterized by new aircraft concepts, novel technologies, and electric flight start-ups. Unlike typical aircraft, AEA topology encompasses a high-power electric powertrain, composed of electric motors, converters, batteries, high-power cabling, and additional avionics [1]. Such configurations present compatibility challenges during the integration stage. Electromagnetic interference (EMI) can present a significant risk to aircraft when not handled properly, with possible dire consequences. The situation is made worse in configurations of all-electric nature, as inherently all systems become susceptible. An AEA powertrain entails high-power components, which are known to be major sources of EMI, and likely to interact harmfully with susceptible systems if not mitigated properly, for instance, in the case of avionics.

When addressing the EMC certification for airborne equipment, the RTCA DO-160 [2] is certainly one of the most referenced civil standards for this subject. However, even though EMC is deeply approached within its guidelines, the content is not directed to aircraft with high-power electric powertrains, characterizing its non-suitability towards AEA. Therefore, in the absence of such a specific standard, guidelines can be taken from automotive regulations, as is the case of CISPR 25, which Annex I provides instructions on testing shielded power supply systems for high voltages in electric vehicles [3].

Amongst the aforementioned sources, electric motors act as a path for common-mode currents through their structure, often referred as a typical source of EMI. When in operation,

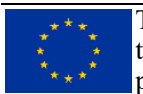

The research leading to these results has received funding from the European Union's Horizon 2020 research and innovation programme, Grant Agreement No 875504 (EASIER). This publication reflects only the authors' view, exempting the European Union from any liability. Project website: http://easier-h2020.eu
}

the interaction between structural and operational components can interfere with neighboring systems [4]. Such behavior can arise from parasitic capacitances between stator windings and motor frame, rotor and stator, rotor and motor frame, from magnets, and even bearings [5]. Furthermore, the structural and operational differences between motor technologies will influence the approach when assessing such parasitics, for instance, due to the different positions of each part. Complementarily, fault conditions are typically a considerable challenge when ensuring EMC at the system level.

The operational regimes implemented into such electric machines will produce voltage and current transients originating from changes in the magnetic fields, which in turn can result in additional emissions. Such transients can be related to variations in operational speed, as in a start-up, breaking, stall, or the application of a speed profile [4]. In the case of aircraft, such profiles are related to the flight envelope and its phases (climb, cruise, and descent) (Fig. 1), which will apply different power levels to the system.

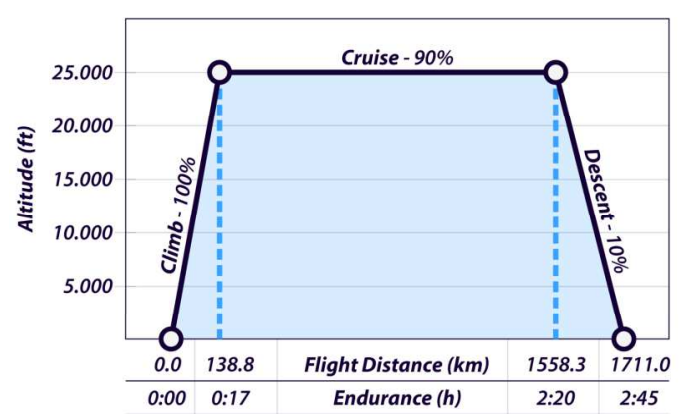

Fig. 1. Flight envelope of a Bombardier Dash 8 Q-300.

This paper briefly assesses the EMI impact of speed variations in a permanent magnet synchronous motor (PMSM) of $1 \mathrm{MW}$ [6], suitable for applications on large aircraft (CS-25) [7]. In order to carry out such analysis, a Bombardier Dash 8 Q-300 [8] aircraft was chosen, from which the flight information was extracted (speed, height, etc.) [9]. For this purpose, a computational simulation was implemented in MATLAB-Simulink, in which the parasitics of the system were properly applied, so the corresponding EMI characteristics could be represented.

The paper is structured as follows. In Section II, a brief overview of the aircraft, and flight profile are presented. As for Section III, the simulation structure is described, as well as the motor characteristics. In Section IV the simulation results are presented and discussed, evaluating the impact of the speed changes towards the CM current. Finally, Section V will eventually present the conclusions regarding the content here discussed.

\section{AIRCRAFT PARAMETERS}

As proposed in [10], a three-phase $1 \mathrm{MW}$ electric motor could be suitable for applications on large aircraft fitting a 
CS-25 classification [7], which encompasses the Bombardier model. Therefore, in order to more accurately represent the speed parameters implemented in such assessment, a flight profile of an operational Dash 8 Q-300 aircraft was obtained from a web-based live air traffic tool, Flight Radar 24 [9]. Based on the technical data of such aircraft [11], which encompasses a pair of PW 123 turboprops [8], a propeller shaft diameter was estimated $(130 \mathrm{~mm})$ and used to convert the obtained speed information (knots) into revolutions per minute (rpm) (Fig. 2).

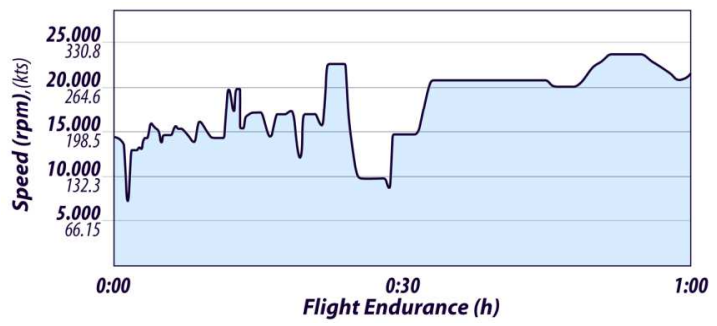

Fig. 2. Speed profile of a Bombardier Dash 8 Q-300.

Such values are in accordance with the speeds evaluated in the design of the machine [6]. From the speed profile obtained, six operation points were considered, 2.5, 5, 7.5, 10, $12.5,15 \mathrm{krpm}$. Furthermore, levels above $15 \mathrm{krpm}$ were not considered in the operational range, as $18 \mathrm{krpm}$ was set as critical speed.

\section{SYSTEM SIMULATION}

To carry out the intended assessment, a generic electric powertrain was modeled in Matlab-Simulink 2020b, consisting of a constant DC source of $1 \mathrm{kV}$, an ideal LISN, common mode (CM) and differential mode (DM) non-optimal filtering solutions, power inverter, and the electric machine (Fig. 3). The switching mode of the inverter is supplied by a field-oriented control (FOC) method, in which a reference speed is supplied to the system, used to provide the rotor angular position [12]. The controller outputs a pulse width modulation (PWM) as a reference, driving the gates of the MOSFETs [12].

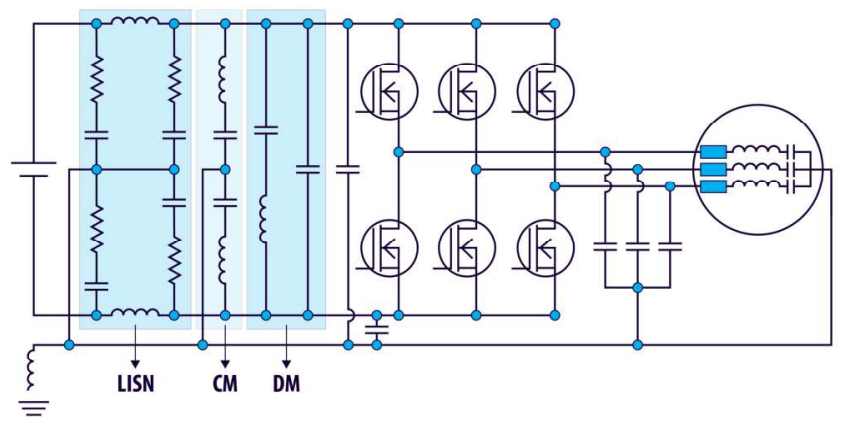

Fig. 3. Electric powertrain (Simulation).

The PMSM was modeled based on the information provided in [6] (TABLE I. ).

TABLE I. PMSM PARAMETERS

\begin{tabular}{|c|c|c|}
\hline Parameter & Value & Units \\
\hline Rated Power & 1 & $\mathrm{MW}$ \\
\hline Rated Torque & 665 & $\mathrm{Nm}$ \\
\hline Nominal Speed & $15 \cdot 10^{3}$ & $\mathrm{rpm}$ \\
\hline
\end{tabular}

This machine operates on a constant torque load, where the motor shaft power increases dependent on the operating speed [13] (Fig. 4).

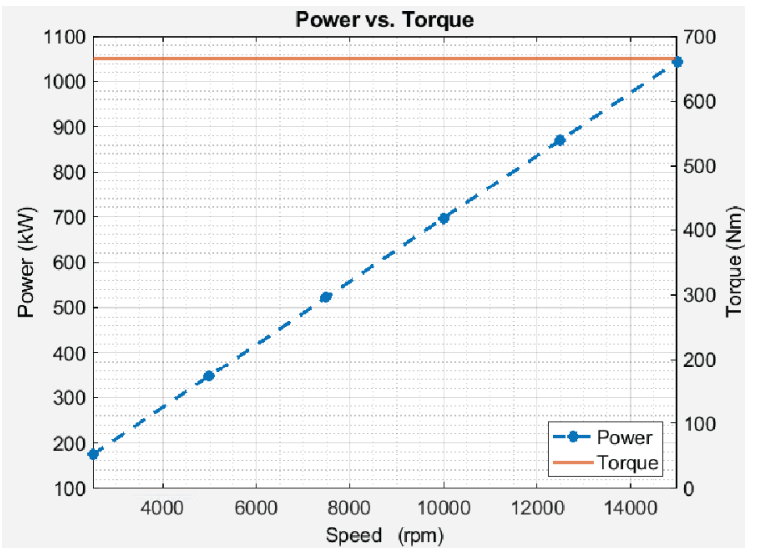

Fig. 4. Power vs. Torque curve.

Such loads are typically applied to electric traction drives, as is the case, and when compared to a variable torque load, constant regime demands higher current levels at lower operational speeds [14]. As for the motor parasitics implemented in the model, they account for the interaction effects of stator and rotor (SR), stator and motor frame (SF), rotor and motor frame (RF), and the bearings $(B)$ [5]. These interactions will ensure a more realistic behavior of the machine, as well as the systems, which in turn will make it possible to analyze CM and DM behavior.

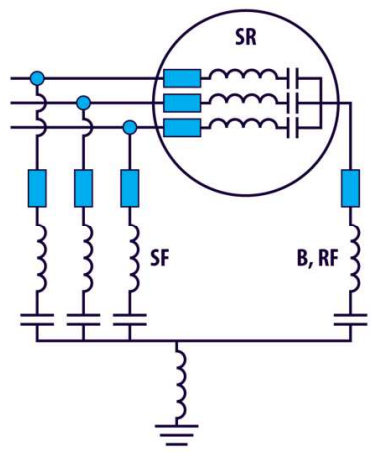

Fig. 5. Motor parasitics.

\section{SiMULATION RESULTS}

When evaluating the current input to the motor, the peakto-peak current increase, although present, is minor. As for the fundamental frequency, the increase can be noticed (Fig. 6) as according to (1).

$$
f=\frac{\omega}{2 \pi}[H z]
$$

In (Fig. 6), a combination of the evaluated speed levels is made, hence, demonstrating a stepwise speed profile implementation. Therefore, the aforementioned change in fundamental frequency in accordance with the operational speed is made visible. 


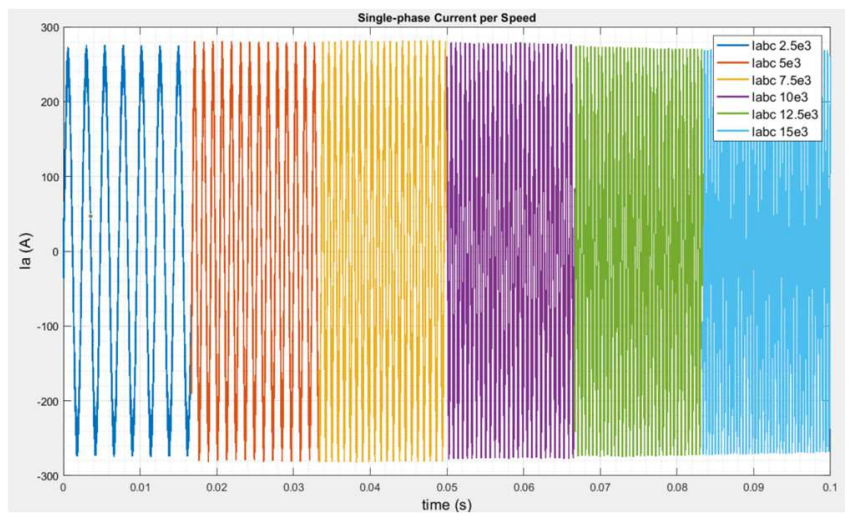

Fig. 6. Single-phase current input to motor.

In order to assess the influence of the switch-mode of the inverter towards the motor power lines, the CM current (Fig. 7) was evaluated. The common-mode current was calculated by the sum of the three-phase currents.

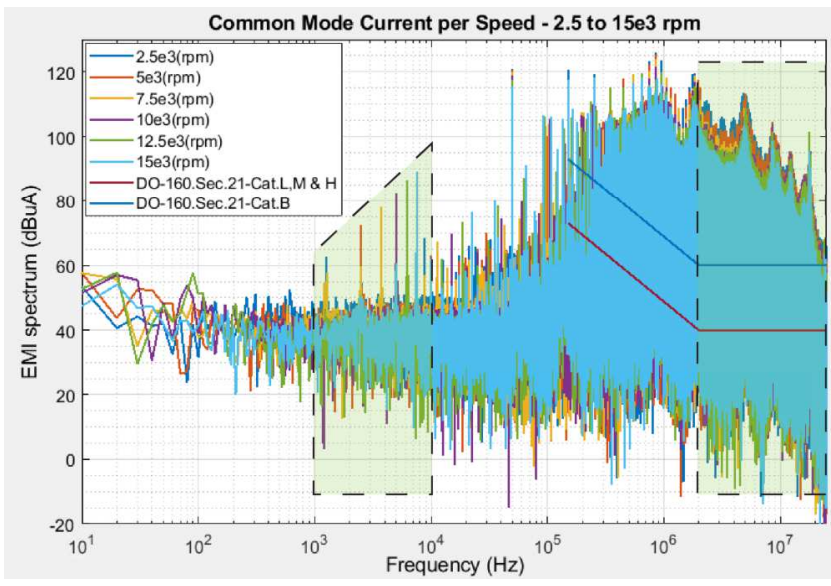

Fig. 7. Common mode current - Motor input.

In (Fig. 7), the increase in fundamental frequency can be seen if the highlighted box on the left, properly corresponding to the implemented speeds, which can be calculated based on (1). Complementarily, when relying on (Fig. 6), it is also possible to estimate the fundamental frequencies of the current sinewaves. Furthermore, an increase in the emission levels of up to $10 \mathrm{~dB}$ is evident in frequencies above $2 \mathrm{MHz}$.

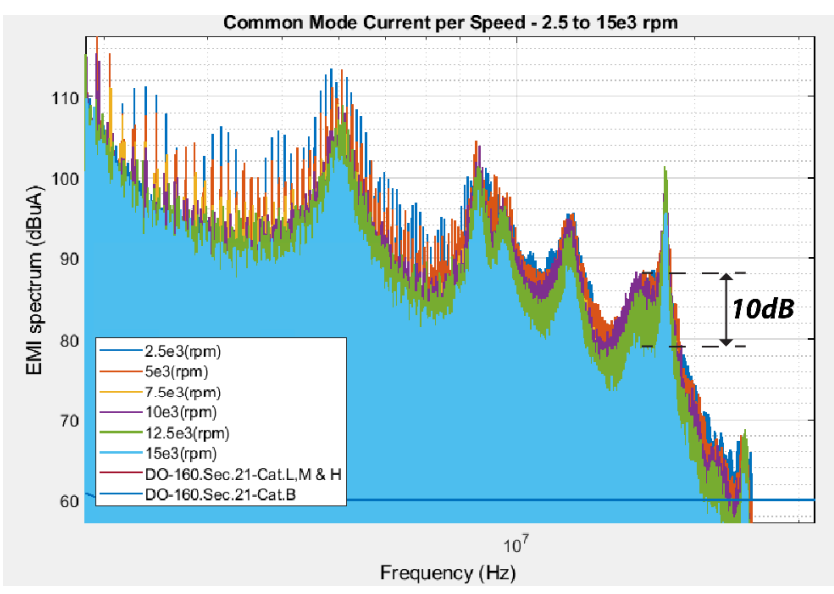

Fig. 8. Common mode current - Motor input (Detail).

Such increase complies with [15], in which it is described as a typical effect of power conversion, originating from the switching mode of inverters, and propagating towards the power lines. Even though in constant torque load operation, lower speeds require an increase in current, only a minor variation was noticed. Nevertheless, the different current levels reflect on the measured CM current for each regime (Fig. 8), thus, the severest emission levels presented were in fact within the slower motor operation points, not at rated speed.

\section{CONCLUSION}

The influence of different powertrain operational points was assessed throughout the implementation of reference speeds to a FOC, in a simulated electric powertrain. Resulting increase in current, even if minor, and fundamental frequency of such states was noticed, which evidence the proper operation of the model. Complementarily, the current levels evaluated are not consistently increasing according to speed change, as noticeable for the lowest speed $(2.5 \mathrm{krpm})$, in which its level was in fact $2.5 \%$ lower than for $5 \mathrm{krpm}$. As for 5 and $7.5 \mathrm{krpm}$, the peak-to-peak currents were equivalent, and the remaining $10,12.5$, and $15 \mathrm{krpm}$, presented reductions of $0.9,1.8$, and $1.7 \%$, respectively.

Nevertheless, the simulation results show that different operation points can influence the resulting EMI. In the case of a constant torque load, lower speeds must be assessed in order to acquire the severest emission levels on which the design of mitigation solutions must be based. According to the implemented regimes and respective results, it is advisable to assess from 5 to $85 \%$ of the rated speed of the motor, as for such differences, emission levels increased up to $10 \mathrm{~dB}$. Nonetheless, the motor application must be taken into consideration, as some operation points could be unused, hence, disregarding such speeds. Furthermore, the impact of such increase towards the proper system operation must be taken into account, as for example in the case of an aircraft where lower speeds could only be operational for short periods of time, or even in non-critical situations, as in ground operations, posing no threats towards primary flight controls.

Therefore, from an EMC design perspective, for PMSM under constant torque load, it does not suffice to evaluate the motor operation under rated parameters as the results may not lead to the proper mitigation solutions.

\section{REFERENCES}

T. C. Cano et al., "Future of Electrical Aircraft Energy Power Systems: An architecture review.," IEEE Trans. Transp. Electrif., 2021, doi: 10.1109/TTE.2021.3052106.

RTCA-DO-160, "Environmental Conditions and Test Procedures for Airborne Equipment," Fed. Aviat. Adm., p. 16, 2011, [Online]. Available:

http://www.faa.gov/airports/resources/advisory_circulars/media/1 50-5345-51A/150 5345 51a.doc.

M. Carl, "International Standard Internationale Tillägg," Policy, vol. 2004, pp. 1-13, 2016.

J. Hu, X. Xu, D. Cao, and G. Liu, "Analysis and optimization of electromagnetic compatibility for electric vehicles," IEEE Electromagn. Compat. Mag., vol. 8, no. 4, pp. 50-55, 2019, doi: 10.1109/MEMC.2019.8985599.

R. R. Riehl, F. de S. Campos, A. F. Alves, and E. R. Filho, "Analysis and Methodology for Determining the Parasitic Capacitances in VSI-fed IM Drives Based on PWM Technique," Induction Mot. - Appl. Control Fault Diagnostics, 2015, doi: 10.5772/61544

L. Zheng, "Mechanical Design and Validation of 1 MW Permanent Magnet Synchronous Machine (PMSM)," University of Illinois, 2018.

EASA, "CS-25 Certification Specifications and Acceptable Means of Compliance for Large Aeroplanes," no. July, 2011. Bombardier Inc, "Bombardier Dash 8 Q-300 Fact Sheet," p. 2, 
2006.

[9] FlightRadar24, "Flight history for aircraft - C-FSOU," 2021. https:/www.flightradar24.com/data/aircraft/c-fsou\#272d61e1 (accessed Apr. 04, 2021).

[10] Z. Nicolas, "New Electric Aircraft Motor Lab Aims For 1MW Electric Airplane Motor," 2019. https:/cleantechnica.com/2019/08/27/new-electric-aircraft-

motor-lab-aims-for-1mw-electric-airplane-motor/ (accessed Feb. 18, 2021).

[11] C. Airlines and T. N. Airport, "Report aircraft, registration ECMPI , operated by Canarias Airlines at the Tenerife North," no. October, 2019.

[12] X. Wang and N. Liu, "Based on SVPWM," 2009 IEEE Veh. Power
Propuls. Conf., no. 4, pp. 1465-1469, 2009.

[13] J. H. G. J. Lansink Rotgerink, F. Happ, and J. J. P. Van Es, "Crosstalk between wire pairs above a composite ground plane," IEEE Int. Symp. Electromagn. Compat., vol. 2016-Novem, pp. 8993, 2016, doi: 10.1109/EMCEurope.2016.7739201.

[14] V. Balaraj, "How to Select a Variable Frequency Drive Based on Load Characteristics," pp. 1-6.

[15] J. Luszcz, "High frequency harmonics emission of modern power electronic AC-DC converters," Int. Conf. Compat. Power Electron. , CPE, pp. 269-274, 2013, doi: 10.1109/CPE.2013.6601168. 